\title{
Comunidades de Prática e aprendizagem docente no ambiente informal do PIBID Ciências
}

Elaine da Silva Machado

Sergio de Mello Arruda

Marinez Meneghello Passos

Virginia lara de Andrade Maistro

\section{Resumo}

Neste estudo, buscamos identificar as capacidades para socialização de experiências e contribuições para a aprendizagem docente, apresentadas pelo blog do PIBID de Ciências de uma universidade do estado do Paraná, e, a partir dessas, refletir sobre os ambientes informais do PIBID, qualitativamente, sob uma proposta mais ampla de aprendizagem, em perspectiva social. O estudo das capacidades para socialização está orientado nas conceituações dos ambientes informais de aprendizagem, no modelo de Comunidades de Prática e na avaliação de outros blogs do PIBID Ciências, em 9 estados do Brasil. Já a investigação da aprendizagem docente no ambiente informal do PIBID Ciências, explora as falas de licenciandos e comunidade externa, em cinco níveis de percepção sistematizados pelo instrumento FAD (Focos da Aprendizagem Docente). Os resultados revelam várias capacidades do ambiente informal do PIBID em promover a aprendizagem docente e limitações interativas relacionadas à ausência de diálogo com a comunidade externa.

Palavras-chave: formação de professores. ambiente informal de aprendizagem. comunidades de prática.

\section{Abstract \\ Communities of Practice and teacher learning in informal environment PIBID Sciences}

In this study, we intend to identify the capabilities for socialization experiences and contributions to teacher learning, presented by the blog PIBID Sciences of State University, in the state of Paraná and, from these, to reflect informal PIBID's environments, qualitatively, from a broader proposal for learning, in social perspective. The study of capabilities for socialization is oriented in concepts of informal learning environments, the Communities of Practice model and evaluation of other blogs PIBID Sciences, in 9 states of Brazil. Already the investigation of teacher learning in PIBID's Sciences informal environment, explores the speeches of teaching student and external community in five levels of perception systematized by the FAD instrument (focus of teacher learning). The results reveal various capabilities of PIBID's informal environment to promote teacher learning and interactive limitations related to absence of dialogue with the external community.

Keywords: educating teachers. informal learning environment.

DOI: Em andamento. 
communities of practice.

\section{Introdução}

É comum as pessoas pensarem que a aprendizagem só ocorre no ambiente escolar, porém temos compreendido a ocorrência da aprendizagem em diferentes locais e contextos, como na vida cotidiana, ao longo da existência, sem obrigar-se à intermediação de um mentor ou da certeza consciente de estar aprendendo. Alguns trabalhos versam sobre a obrigatoriedade do homem em aprender para existir e pelo tempo que existir, como os estudos de Charlot (2000) e outros se voltam à ocorrência da aprendizagem de Ciências por jovens em outros ambientes, como os estudos de Alves, Passos e Arruda (2010), Colley, Hodkinson e Malcom (2002) e Astor-Jack et al. (2007).

Com o paradigma da aprendizagem em diferentes locais e momentos, novos estudos e novas definições para o aprendizado têm surgido. Destacamos a divulgada pela Comissão Europeia e traduzida por Arruda e colaboradores:

"Aprendizado formal: aprendizado fornecido tipicamente por uma instituição de educação ou treinamento, estruturado (em termos de objetivos de aprendizagem, tempo de aprendizado ou sustentação) e que leva a uma certificação. É intencional, do ponto de vista do aprendiz. Aprendizado não formal: não é fornecido por uma instituição educacional ou de treinamento e não leva a uma certificação. Entretanto é estruturada (em termos de objetivos, tempo e suporte à aprendizagem). É intencional, do ponto de vista do aprendiz. Aprendizado informal: resulta das atividades do dia a dia, relacionadas ao trabalho, família ou lazer. Não é estruturada (em termos de objetivos, tempo e suporte à aprendizagem) e normalmente não leva a uma certificação. $O$ aprendizado informal pode ser intencional, mas na maioria das vezes é não intencional ou incidental" (EUROPEAN COMMISSION, 2001, p. 32-33 apud ARRUDA et al. 2013, p. 483-484).

A partir dessas definições, as formas de aprender foram organizadas em situação formal, não formal ou informal e posteriormente os ambientes da aprendizagem informal também foram organizados pelo Conselho Nacional de Pesquisa (NRC - NATIONAL RESEARCH COUNCIL, 2009) em relatório publicado. Diante disso, o aprendizado informal em relação aos ambientes pode efetivar-se em: ambientes planejados, em programas fora da escola e para adultos e em ambientes informais do cotidiano, sendo este último o ambiente que exploramos neste estudo. Segundo o NRC, os ambientes informais do cotidiano estão presentes na vida diária dos humanos e podem se estender por toda ela. Acolhem conversas diárias com a família e com os colegas, os hobbies pessoais, e grifamos o envolvimento com a mídia e o uso da tecnologia (NRC, 2009). 
Sobre os ambientes planejados, versa o relatório que fazem parte os museus, centros de ciência, jardins botânicos, zoológicos, aquários e livrarias, enquanto programas fora da escola e programas para adultos abrigam os programas de verão, da terceira idade e outros programas onde a escolha de participação dependa do aprendiz ou do seu responsável (NRC, 2009).

Concentramos nossa investigação nos ambientes informais do cotidiano, que estão relacionados ao aprendizado informal pelo envolvimento com a mídia e o uso da tecnologia, e voltamos especificamente à análise do blog do Programa Institucional de Bolsa de Incentivo à Docência - PIBID, destinado à área de Ciências, no curso de Ciências Biológicas desta universidade paranaense. Por tratarmos de um ambiente de aprendizagem no ciberespaço, levamos em conta a sua capacidade interativa, seu fluxo livre de participações e socializações e suas possibilidades para a formação inesperada de comunidades integradas.

\section{Comunidades de Aprendizagem e Comunidades de Prática}

O ambiente que nos destinamos a investigar possui uma dinâmica ímpar de condução, porque permite uma situação de aprendizado livre e por socialização, descrita por Schugurenski (2000), como aquela situação que envolve a participação de indivíduos em uma experiência de aprendizado com ou sem intenção inicial e que permite também aprendizagem tardia aquele encontro dos indivíduos. Podemos pensar a partir disso que nos contextos onde ocorre reaproximação dos membros da comunidade, a aprendizagem não tem um fim em si, pois o membro que aprendeu tardiamente pode compartilhar com os outros a sua experiência. Assim, quando esse evento ocorre continuamente, com diferentes membros no ciberespaço, perceberemos o fluxo de participação da comunidade e da aprendizagem por socialização. As capacidades do fluxo de participação estão reunidas com a ideia de comunidade virtual por Pedro (2013), em dissertação intitulada: Sites de Redes Sociais como Ambiente Informal de Aprendizagem Científica, sob a orientação de Passos.

Essas comunidades podem assumir uma perspectiva social e passarem a Comunidades de Prática, comprometendo-se na evolução do saber de toda a comunidade que a integra e do próprio domínio que as reúne (nesse caso a licenciatura, a formação docente e o ensino e a aprendizagem das Ciências). A ideia de comunidades de prática está descrita por Lave e Wenger (1991) e representa um modelo mais eficaz de aprendizagem que deixa de ser simples e passa a ser social e, por isso, tal teoria é uma nova forma de socializar conhecimentos. As comunidades de prática são formadas por grupos de pessoas que se engajam, de maneira compartilhada, em processo de aprendizagem coletiva, se interessam por aprender mais e fazer melhor pelo domínio e incentivam novas abordagens para os problemas experienciados.

Segundo Wenger (2013, p. 249), essas pessoas se reúnem em ambientes formais, não formais e informais (como escola, casa, trabalho e passatempos), com entendimento sobre o 
aprender e suas funções de maneira distinta: os indivíduos entendem o aprender como uma questão de se envolver e contribuir para as práticas de suas comunidades; as comunidades entendem o aprender como uma questão relacionada ao "refinamento" da sua prática e a garantia de novas gerações de membros; e as organizações entendem o aprender como uma questão relativa à manutenção das comunidades de prática interconectadas, "pelas quais a organização aprende o que aprende e, assim, torna-se efetiva e valiosa como organização".

A ideia de existência de comunidades de aprendizagem em ambiente virtual é facilmente possível de ser notada (como em comunidades no Facebook), já a comunidade de prática é uma ideia bem intencional e organizada. Entendemos ambientes informais de aprendizagem, o blog que vamos analisar e vimos a sua dinâmica e em especial a sua capacidade espontânea para formar grupos que podem evoluir o aprendizado pela partilha de experiências. Podemos então voltar os olhos para o programa PIBID e os espaços informais do PIBID de Ciências que nos propomos a investigar.

\section{O PIBID de Ciências em estudo}

O PIBID - Programa Institucional de Bolsa de Iniciação à Docência - foi criado no ano de 2007 e apresentado pela Fundação Capes (Centro de Aperfeiçoamento de Pessoal de Nível Superior) como possibilidade para articular a escola e a universidade durante a formação de professores, por meio da atuação dos licenciandos em escolas da educação básica da rede pública de ensino, por projetos de pesquisa, ensino e extensão. Para aderir ao programa, respondem ao edital da Capes as Instituições de Ensino Superior - IES públicas e privadas com e sem fins lucrativos que oferecem cursos de licenciatura e que cumprem com a entrega de projetos e subprojetos, devidamente compostos para as áreas de conhecimento que desejam programar, por exemplo, Ciências Biológicas, Química e Física (BRASIL, 2007).

Em contato com o Centro de Ciências Biológicas - CCB - desta universidade paranaense, reconhecemos o PIBID Ciências Biológicas e o PIBID Ciências. Entre eles escolhemos tratar o PIBID Ciências por duas razões: 1 - Tinha a proposta de ser dirigido a outros estudos, tínhamos contato direto com o grupo, com permissão provisória de coleta de dados e de participação das discussões e, ainda, o apoio dos coordenadores para observar as suas reuniões semanais; 2 - 0 subprojeto desse programa está composto de maneira bem ampla, seu acesso via blog é facilitado, é um dos poucos que expõe o seu cronograma de atividades e, também, porque adota em seu plano de ação a produção de um blog para socialização das suas experiências, ou seja, socializar o saber em ambiente informal é um objetivo desse grupo.

Suas atividades se iniciaram em 2011 com ações propostas diversas, dentre elas a produção de material didático, dramatizações para o ensino de Ciências, pesquisa e teste de novas propostas, registro de aulas nas escolas e exposição de registros no blog. Diante desse conjunto 
de ações, ficamos nos questionando sobre as capacidades e limitações do ambiente informal do PIBID - Ciências (que identificaremos a partir de agora como PIBID-C), em promover-se como um ambiente informal de aprendizagem docente mantenedor de comunidades de prática, por meio da socialização de suas experiências.

Para analisarmos tal capacidade de aprendizagem e socialização do ambiente necessitamos medir sinais externos de interação, como quantidade de membros seguidores do blog, número de visitantes e fluxo de postagens de comentários ou depoimentos no ambiente dessa comunidade. Ao contrário dos outros pontos que respondemos por quantificações, ou fichamentos, os conteúdos dos comentários e relatos precisam ser analisados com instrumentos qualitativos mais específicos, o que nos levou aos FAD - Focos da Aprendizagem Docente.

\section{FAD - Focos da Aprendizagem Docente}

Os Focos da Aprendizagem Docente - FAD foram propostos por Arruda, Passos e Fregolente (2012) em analogia aos Focos da Aprendizagem Científica - FAC, apresentados em um dos relatórios do NRC, intitulado Learning Science in Informal Environments: People, Places and Pursuits (2009). Os Focos da Aprendizagem Científica (FAC) organizam seis habilidades científicas específicas denominadas strands of science learning que se manifestam em ambientes informais. Quando registrada a ocorrência de tais habilidades, podemos afirmar que houve aprendizagem científica no ambiente. Essas habilidades foram traduzidas por Arruda, Passos e Fregolente (2012) como focos e organizadas na escala de 1 a 6, sendo: 1) Foco do Interesse Científico; 2) do Conhecimento Científico; 3) da Prática Científica; 4) da Reflexão sobre a Ciência; 5) da Comunidade Científica; e, 6) da Identidade Científica.

Cada foco representa uma dimensão do aprendizado científico e para os autores o progresso de um contribui para o desenvolvimento do outro, igualmente fundamental para a aprendizagem científica em qualquer configuração. Os autores Arruda, Passos e Fregolente (2012) refletiram sobre os focos no contexto da aprendizagem docente e sobre os sentidos expressos pelos professores em formação e contribuíram com um novo instrumento para análise da aprendizagem docente chamado FAD, não mais com seis, e sim com cinco focos por considerarem teoria e prática (focos 2 e 3 dos FAC) "amalgamadas" (p. 29-32) ou inseparáveis. Os cinco focos podem ser lidos no Quadro 1 e nos apoiam nas investigações sobre a presença de aprendizagem docente. 
Quadro 1 - Instrumento para análise da aprendizagem docente FAD -

Focos da Aprendizagem Docente

Foco 1 [interesse pela docência]. O estudante experimenta interesse, envolvimento emocional, curiosidade, motivação, mobilizando-se para exercer e aprender cada vez mais sobre a docência.

Foco 2 [conhecimento prático da docência]. A partir do conhecimento na ação e com base na reflexão na ação, o estudante desenvolve o conhecimento de casos, um repertório de experiências didáticas e pedagógicas que orientam a sua prática cotidiana in actu.

Foco 3 [reflexão sobre a docência]. Frente a novos problemas originados de sua prática, os quais não conseguiu resolver no momento em que ocorriam, o futuro professor, com base em instrumentos teóricos, analisa a situação sistematicamente, envolvendo-se com a pesquisa e reflexão a posteriori sobre sua prática e o seu conhecimento acumulado sobre ela, de modo a resolver os problemas inicialmente detectados. Trata-se de desenvolver a dimensão da pesquisa no futuro professor.

Foco 4 [comunidade docente]. O estudante participa de atividades desenvolvidas em uma comunidade docente, aprende as práticas e a linguagem da docência com outros professores ou futuros professores, assimilando valores dessa comunidade e desenvolvendo a reflexão coletiva.

Foco 5 [identidade docente]. 0 estudante pensa sobre si mesmo como um aprendiz da docência e desenvolve uma identidade como alguém que se tornará futuramente um professor de profissão.

Fonte: Arruda, Passos e Fregolente, 2012, p. 26

\section{Metodologia e coleta de dados}

Desenvolvemos investigação qualitativa na perspectiva de Bogdan e Biklen (1982), sendo os dados recolhidos em forma de palavras e imagens, analisados em "[...] sua riqueza, respeitando, tanto quanto possível, a forma em que estes foram registrados ou transcritos" (p. 48). Observamos o ambiente PIBID-C em busca de indícios de interações e trocas ou exposições de experiências docentes, mesmo as solitárias. Ao percebermos a sua diversidade de informações, adotamos análise de conteúdo, fundamentada em Bardin (2006) e estendemos a análise para mais 12 blogs pertencentes a diferentes IES, a fim de criarmos codificações e categorizações abrangentes para a primeira (blog PIBID-C). Tais categorias são, na descrição do autor, “[...] rubricas ou classes, as quais reúnem um grupo de elementos sob um título genérico, 
agrupamento esse efectuado em razão dos caracteres comuns destes elementos" (BARDIN, 2006, p. 117).

Esses caracteres nos ajudaram a compor uma ficha de capacidades para a socialização das experiências, medir interações e supor competências ao ambiente informal do projeto PIBID. Para análise dos comentários usamos os FAD (Focos da Aprendizagem Docente), com o objetivo de evidenciar a presença de relatos significativos para a promoção da aprendizagem docente feitos por visitantes e pelos licenciandos do ambiente. A identidade dos autores das falas foi preservada sob orientação de Demo (2008). Esclarecemos que nosso corpus foi constituído pela ficha de avaliação do blog, um comentário externo e cinco relatos internos.

\section{Apresentação e análise dos dados}

Iniciamos a análise de conteúdo do ambiente PIBID-C e, diante da diversidade de informações, como apontamos anteriormente, estendemos a visita para outros blogs do PIBID/Ciências Biológicas criados por outras 12 universidades (federais e estaduais), em 9 estados do Brasil: Paraná, Santa Catarina, São Paulo, Minas Gerais, Goiás, Sergipe, Ceará, Amapá e Rio Grande do Sul. A seleção dos 12 blogs foi feita sobre o filtro do GOOGLE "blog PIBID Ciências Biológicas" e não responde necessariamente aos 12 primeiros blogs classificados pelo filtro, porque alguns deles não estavam mais ativos e isso nos remetia ao próximo indicado. Esses blogs selecionados serviram-nos para a construção da ficha de classificação do ambiente informal PIBIB-C, que apresentamos no Quadro 2. As categorias de análise contidas nesta ficha representam, dentro da amostra total analisada (13 blogs), o que um ambiente informal do PIBID está trazendo para as propostas de: socializar suas experiências, promover interações com a aprendizagem docente e cultivar comunidades de práticas.

Quadro 2 - Ficha para as capacidades do ambiente informal de aprendizagem docente do PIBID Ciências

\begin{tabular}{|c|c|c|c|c|}
\hline & CATEGORIAS DE ANÁLISE & DESCRIÇÃO & PRESENÇA & $\begin{array}{l}\text { CONSIDERAÇÕES DA } \\
\text { PRESENÇA }\end{array}$ \\
\hline 1 & $\begin{array}{l}\text { ACESSO AO CONCEITO DO } \\
\text { PIBID }\end{array}$ & Esclarece o que é o Programa. & $x$ & $\begin{array}{l}\text { Seção: Objetivos e } \\
\text { finalidades. }\end{array}$ \\
\hline 2 & $\begin{array}{l}\text { ACESSO AOS BENEFÍCIOS } \\
\text { DO PIBID }\end{array}$ & $\begin{array}{l}\text { Esclarece sobre a valorização } \\
\text { da docência pelo programa - } \\
\text { Concessão de bolsa. }\end{array}$ & $x$ & Não revela valores. \\
\hline 3 & ACESSO AO SUBPROJETO & $\begin{array}{l}\text { Disponibiliza acesso ao } \\
\text { subprojeto da área específica, }\end{array}$ & $\mathrm{X}$ & $\begin{array}{l}\text { Seção: Objetivos e } \\
\text { finalidades. }\end{array}$ \\
\hline
\end{tabular}

R. B. E. C. T., vol 8, Ed. Sinect, jan-abr.2015 ISSN - 1982-873X

DOI: Em andamento. 


\begin{tabular}{|c|c|c|c|c|}
\hline & & $\begin{array}{l}\text { objetivos, ações e plano de } \\
\text { trabalho. }\end{array}$ & & $\begin{array}{l}\text { e } \\
\text { Seção: Plano de } \\
\text { trabalho. }\end{array}$ \\
\hline 4 & $\begin{array}{l}\text { ACESSO AO } \\
\text { CRONOGRAMA DE } \\
\text { ATIVIDADES }\end{array}$ & $\begin{array}{l}\text { Disponibiliza acesso às } \\
\text { atividades a serem realizadas } \\
\text { pelo subprojeto. }\end{array}$ & $X$ & $\begin{array}{l}\text { Ausente 2014, porém } \\
\text { possui postagens } \\
\text { atualizadas das } \\
\text { atividades desenvolvidas. }\end{array}$ \\
\hline 5 & $\begin{array}{l}\text { ACESSO A UNIDADES } \\
\text { DIDÁTICAS (UD) }\end{array}$ & $\begin{array}{l}\text { Disponibiliza acesso às } \\
\text { unidades didáticas (materiais } \\
\text { criados, roteiros de práticas e } \\
\text { planos de aula) desenvolvidas } \\
\text { ao longo do projeto. }\end{array}$ & $X$ & $\begin{array}{l}\text { Em formato de breves } \\
\text { relatos ilustrados. } \\
\text { Seção: Conteúdo e } \\
\text { Escolas. }\end{array}$ \\
\hline 6 & $\begin{array}{l}\text { INTENÇÃO DE } \\
\text { SOCIALIZAÇÃO VIA BLOG }\end{array}$ & $\begin{array}{l}\text { Declara o blog avaliado que é } \\
\text { sua intenção socializar } \\
\text { experiências docentes através } \\
\text { desse espaço virtual. }\end{array}$ & $X$ & $\begin{array}{l}\text { Seção: Plano de } \\
\text { trabalho. }\end{array}$ \\
\hline 7 & $\begin{array}{l}\text { ID - NÚMERO DE } \\
\text { MEMBROS DO } \\
\text { SUBPROJETO }\end{array}$ & $\begin{array}{l}\text { Identifica o número de } \\
\text { Membros participantes do } \\
\text { Subprojeto em análise, a } \\
\text { incluir nomes. }\end{array}$ & $X$ & $\begin{array}{l}\text { Seção: Integrantes. } \\
\text { Revela: coordenadores, } \\
\text { bolsistas, supervisorese } \\
\text { escolas. }\end{array}$ \\
\hline 8 & $\begin{array}{l}\text { ID - NÚMERO DE } \\
\text { SEGUIDORES DO } \\
\text { AMBIENTE/COMUNIDADE }\end{array}$ & $\begin{array}{l}\text { Identifica o número de } \\
\text { seguidores na rede ou } \\
\text { número de visitantes por } \\
\text { contador. } \\
\text { (Nos auxilia a perceber a } \\
\text { presença da comunidade } \\
\text { externa). }\end{array}$ & & \\
\hline 9 & $\begin{array}{l}\text { POSTS - COMENTÁRIOS } \\
\text { DE VISITANTES - } \\
\text { DEPOIMENTOS }\end{array}$ & $\begin{array}{l}\text { Apresenta comentários nas } \\
\text { postagens pelos visitantes ou } \\
\text { membros da comunidade. } \\
\text { (Nos auxilia a perceber a } \\
\text { presença de comunidades e } \\
\text { socialização das experiências } \\
\text { Pibidianas). }\end{array}$ & $X$ & $\begin{array}{l}\text { Postagem: Setembro de } \\
\text { 2011. Título: Jogos } \\
\text { como estratégias. }\end{array}$ \\
\hline
\end{tabular}




\begin{tabular}{|c|c|c|c|c|}
\hline 10 & $\begin{array}{l}\text { CONTEÚDO OBJETIVO DA } \\
\text { BIOLOGIA/CIÊNCIAS }\end{array}$ & $\begin{array}{l}\text { Disponibiliza conteúdos } \\
\text { objetivos (específicos, } \\
\text { epistêmicos) da biologia ou } \\
\text { área em análise. }\end{array}$ & & \\
\hline 11 & $\begin{array}{l}\text { CONTEÚDO OBJETIVO DA } \\
\text { DOCÊNCIA }\end{array}$ & $\begin{array}{l}\text { Disponibiliza conteúdos } \\
\text { objetivos (específicos, } \\
\text { epistêmicos) da licenciatura, } \\
\text { seja sobre formação ou } \\
\text { atuação docente, ou, ainda, } \\
\text { conteúdos objetivos da } \\
\text { aprendizagem. }\end{array}$ & & \\
\hline 12 & $\begin{array}{l}\text { EVENTOS DA ÁREA } \\
\text { DOCENTE }\end{array}$ & $\begin{array}{l}\text { Divulga eventos científicos e } \\
\text { viabiliza o acesso na } \\
\text { publicação. }\end{array}$ & $X$ & $\begin{array}{l}\text { Somente dos que } \\
\text { participam com } \\
\text { apresentação de } \\
\text { trabalhos. }\end{array}$ \\
\hline 13 & $\begin{array}{l}\text { INDICAÇÕES A AMBIENTES } \\
\text { NÃO FORMAIS DE } \\
\text { APRENDIZAGEM } \\
\text { CIENTÍFICA }\end{array}$ & $\begin{array}{l}\text { Divulga acesso a ambientes } \\
\text { não formais de aprendizagem } \\
\text { das Ciências, como museus, } \\
\text { clubes de exploração } \\
\text { ecológica, de astronomia, de } \\
\text { birdwatching, jardim botânico } \\
\text { e outros. }\end{array}$ & $x$ & $\begin{array}{l}\text { Somente para outros } \\
\text { ambientes informais - } \\
\text { Blogs - do PIBID - } \\
\text { Áreas e Estados } \\
\text { variados. }\end{array}$ \\
\hline
\end{tabular}

Fonte: Os pesquisadores.

Organizamos as competências da ficha em três capacidades principais: A) promover interação da comunidade externa com o Programa PIBID, seus objetivos e proposta; B) promover aprendizagem docente pela socialização de suas experiências; e, C) desenvolver e abrigar comunidades de prática.

A) promover interação da comunidade externa com o Programa PIBID, seus objetivos e proposta: responderam os itens $1,2,3$ e 4 e revelaram que há um compromisso do ambiente PIBID-C em esclarecer o que é o projeto PIBID e compartilhar suas intenções. Podemos captar facilmente no ambiente, seções específicas em que estão expostos esclarecimentos sobre os objetivos, função dos envolvidos, ações previstas e cronograma de atividades do subprojeto. Os integrantes estão identificados a partir do coordenador geral, seguido pela coordenadora do subprojeto, bolsistas, suplentes e escolas participantes com seus devidos professores supervisores. O plano de trabalho revela entre os 11 procedimentos adotados para o alcance dos objetivos do grupo, a posição 10: "Produção de blog para socialização de experiências". A

DOI: Em andamento. 
presença do cronograma é um item pouco comprido pelo que podemos perceber em contato com os outros ambientes, mas embora o PIBID-C o tenha exposto, não o manteve atualizado para o ano de 2014.

B ) promover aprendizagem docente pela socialização de suas experiências: respondem os itens 5, 6 e 9. Entendemos que para essa socialização ocorrer, no mínimo as experiências do grupo devem estar postadas, fotografadas, e passíveis de entendimento e reprodução. 0 ambiente PIBID-C atualmente expõe suas experiências com breves relatos e fotos, mas quando iniciou suas atividades fazia seus registros com maiores detalhes sobre os resultados das práticas na sala de aula. Embora breve, mantém o registro ilustrado de práticas inovadoras e um fluxo contínuo de postagens das novas experiências. Já o número de comentários sobre essas experiências não apresenta fluxo ou disposição para mantê-lo, conforme analisamos no item 9. Quando o membro de uma comunidade do PIBID Física desta mesma universidade (Professor ' $P$ '), interage e convida para a ação e reflexão, não recebe qualquer resposta no ambiente recém-inaugurado e nenhum outro registro de comentário foi identificado desde então (2011). Esse resultado de baixa postagem de comentários pela comunidade externa ou até mesmo entre os membros, pode ser percebido nos outros 8 estados que estudamos e hoje essa ausência nos inviabiliza a analisar diálogos interativos nesses ambientes e confere solidão à possível comunidade.

C) capacidades para desenvolver e abrigar comunidades de prática: respondem para essa capacidade os itens 7 e 12 e estão ausentes os itens 9 (que também deve ser considerado aqui), 10, 11, 12 e 13. Sendo assim, o PIBID-C viabiliza um espaço que permite conhecer seus integrantes e suas práticas, aproxima a comunidade externa com a divulgação de eventos científicos da área e incentiva participações, embora faça com pouca abrangência, uma vez que divulga apenas os eventos dos quais participa. Quanto aos itens ausentes, o ambiente não cultiva diálogos com a comunidade externa, não viabiliza a troca de práticas, não compartilha conteúdos objetivos da biologia ou objetivos da licenciatura (cabe destacar que após a coleta de dados, continuamos acessando o blog e nele têm sido postadas informações relativas aos objetivos da Ciência, Biologia, Docência e Aprendizagem) e não viabiliza acesso a ambientes não formais de aprendizagem da Ciência de forma a integrar outras comunidades, sejam elas pertencentes a museus, jardins botânicos ou parques ecológicos da cidade. Por outro lado possibilita a interação com outros ambientes informais do PIBID Ciências Biológicas e outras áreas, como Química, Física e História, em diferentes estados.

Outras questões importantes agregamos ao item 8 e novamente ao item 9. Eles nos permitem apontar que a presença de um contador de acesso da página ou do número de visitantes, auxiliaria nas pesquisas da área com dados e incentivaria participações externas, assim como a adoção da intenção em interagir com a comunidade externa e de efetivar-se um ambiente 
para diálogos. A limitação do diálogo também ocorre nas outras 12 universidades, ou seja, é algo que devemos trabalhar no programa PIBID e não apenas no PIBID-C.

Para a análise das capacidades do ambiente como um espaço de promoção da aprendizagem docente, procuramos identificar a presença dos FAD (Focos da Aprendizagem Docente) em um comentário externo e cinco relatos internos. Para relembrarmos, os FAD são compostos por: foco 1: interesse pela docência; foco 2: conhecimento prático da docência; foco 3 : reflexão da docência; foco 4: comunidade docente; foco 5 : identidade docente.

Foco 1 - Interesse pela docência: Identificamos a presença do foco 1 no ambiente PIBID-C no comentário externo da postagem sobre o jogo da velha, enviado pelo professor supervisor ' $P$ '. O trabalho do seu grupo (ele e os seus pibidianos na escola pública) é criar novos experimentos interessantes e acessíveis para a Física. Sua fala remete ao interesse, curiosidade e motivação pela docência. Percebemos também que o professor ' $P$ ' mobiliza-se para exercer e aprender mais sobre a docência e tenta aprender em interação, socializando-se com outros membros do programa e participantes desse ambiente:

“Professor P - Olá pessoal do PIBID Ciências. Meu nome é 'P' e sou Supervisor de um dos Grupos do PIBID Física [...]. Nosso grupo trabalha desenvolvendo experimentos científicos de baixo custo e na produção de material didático relacionado. Nosso link é: http://pibid[...]wordpress.com/. Que tal juntarmos forças?!". (03 out. 2011 - Interação externa - Postagem: Jogo da Velha)

Por entender a aprendizagem docente como prática de uma comunidade ou a envolver a participação em grupos de professores, além da presença do foco 1 para a aprendizagem docente, também identificamos na fala de " $\mathrm{P}$ " o foco 4 , que nos diz respeito à comunidade docente.

Foco 2 - Conhecimento prático da docência: Os autores dos FAD, Arruda, Passos e Fregolente (2012, p. 40-41), preveem nesta categoria apresentações de conhecimento de casos, de repertórios de experiências didáticas e pedagógicas construídas a partir do conhecimento na ação sob a base da reflexão na ação. Identificamos a presença desse foco em trecho da ata sobre a atividade do barbante feita pelo bolsista ' $G M$ ' e no relato sobre a aplicação do jogo da velha como estratégia para o ensino de "qualquer conteúdo":

"Bolsista GM - Em outra visita à escola W. D., dessa vez no período da tarde, foi realizada com os alunos da 6a série a dinâmica do barbante, na qual cada participante fala informações suas e passa a vez e o barbante para outra pessoa, formando uma teia no centro do círculo. A dinâmica foi trabalhosa, pois os alunos estavam muito agitados. Foi sugerido que os estagiários do PIBID falassem sobre drogas com os alunos, pois existem nessa escola muitos 
problemas nesse sentido. Discutiu-se, então, estratégias para tratar desse assunto de modo interessante aos alunos" (07 de julho de 2011).

"Bolsista N-O interessante deste jogo é que une competição e cooperação de forma divertida e animada que atrai muitos alunos para a atividade. Durante a realização do jogo o professor pode verificar se os objetivos de sua aula foram cumpridos, então o professor vê o resultado de sua aula ao final dela. É também interessante que muitas vezes não há um vencedor, resultando em "velha", há um empate entre os grupos, não alimentando discussões pela competição" (29 de setembro de 2011 - Postagem Jogo da Velha).

Notamos na ata de 'GM' as reações negativas da prática e os improvisos necessários pelos Pibidianos durante a ação para superá-las, porém a comunidade não compartilha explicitamente a forma adotada para a superação, nem maiores detalhes sobre as dificuldades enfrentadas. Já no relato de ' $\mathrm{N}$ ' identificamos a exposição dos conhecimentos originados na ação durante a descrição das reações positivas dos alunos e da frequência dos empates no jogo. Também notamos em ' $N$ ', aspectos da reflexão na ação durante as indicações para o aproveitamento do tempo e do espaço, direcionado à verificação dos objetivos cumpridos e reflexão sobre o resultado da aula, a ser feita pelo professor durante e ao final da sua ação.

Foco 3 - Reflexão sobre a docência: Foi possível identificar o foco 3 pelas reflexões sobre a docência após a ação, mas em outro formato, pois não temos a exposição de um conflito originado na prática e resolvido sob a luz da teoria e reflexão, mas igualmente temos a reflexão sobre a viabilidade de uma prática após a ação em sala de aula e o uso de conceitos teóricos acumulados durante a formação. As reflexões são sobre o uso do teatro para auxiliar o educador e motivar o aluno a aprender:

\begin{abstract}
"Bolsistas PIBID - ID desconhecida: Avaliamos que as aulas práticas e o uso do teatro servem de estratégia e podem auxiliar o educador a retomar um contexto já abordado, estabelecer com seus alunos uma nova visão sobre um mesmo tema. Ao compreender um conteúdo trabalhado em sala de aula, o aluno expande sua reflexão sobre os fenômenos que acontecem à sua volta, desperta curiosidade e aumenta o interesse, uma vez que este tipo de modalidade didática pode facilitar, entre outros fatores, a observação de fenômenos estudados em aulas teóricas" (19 de março de 2012).
\end{abstract}

Esse foi o foco mais difícil de ser encontrado porque, como informamos na seção anterior, quando o blog iniciou suas postagens em 2011, ele tinha uma exposição um pouco mais reflexiva sobre as experiências do grupo, depois ele foi se transformando e voltando-se mais à objetividade. Atualmente as falas reflexivas sobre as práticas aplicadas ou sobre outras experiências da docência vividas pelo grupo, são raras. 
Foco 4: Comunidade Docente e Foco 5: Identidade Docente: Os focos 4 e 5 também foram identificados na análise. Sobre as comunidades percebemos na declaração de 'KG', que os membros do PIBID participam de atividades desenvolvidas por comunidades científicas e que essas comunidades também representam comunidades docentes que assimilam valores e desenvolvem reflexão coletiva sobre a prática.

"Bolsista KG - Nós participantes do PIBID pretendemos aumentar o número de publicações, enviando-as a eventos, eventos estes cuja participação é de extrema importância, dentre as quais as trocas de experiências em torno da docência, junto a outros participantes" (26 de março de 2012).

"Bolsistas PIBID A\&N - primeiro contato com os alunos da $7 \underline{a}$ série $D$ foi estabelecido. [...]. A dinâmica do barbante criou um clima agradável e de descontração entre todos os participantes, incluindo os alunos, a professora da escola e nós do PIBID" (18 de junho de 2011).

Sobre o foco da identidade docente (5), a fala do bolsista ' $K G^{\prime}$ ' nos revela a identidade ampla que o Pibidiano pode assumir no grupo que ocupa, pois ela abrange ser Pibidiano e membro de uma comunidade docente, professor e membro de uma comunidade científica. Já no relato de 'A\&N', percebemos uma forma exclusiva de identidade, onde o licenciando não se identifica como aluno, nem como "a professora da escola" no episódio vivido, e sim como um Pibidiano participante de uma comunidade "nós do PIBID".

\section{Considerações finais}

Consideramos que fichar o ambiente foi válido, entre outros resultados, também porque nos colocou em contato com outros blogs, estados e IES, nos permitindo olhar o programa e seus ambientes informais de aprendizagem amplamente. $O$ instrumento FAD de Arruda, Passos e Fregolente (2012), por sua vez, nos permitiu identificar o ambiente informal do PIBID-C como capaz de promover interação com a aprendizagem docente genuína, no sentido de que os relatos expostos apresentam evidências de um e mais focos provenientes da aprendizagem docente, sejam eles do interesse pela docência (Professor ' $P$ '), do conhecimento prático (pelo Bolsista GM e N), reflexão sobre a docência (bolsistas PIBID) ou comunidade e identidade docente (Bolsista KG e $A \& N)$.

Podemos assim considerar o ambiente PIBID-C portador de capacidades para promover a aprendizagem docente pelo compartilhamento contínuo de suas experiências, e em prover experiências docentes significativas a comunidades e visitantes, por meio dos relatos genuínos, assim como novas aprendizagens e novas reflexões ao campo, a partir desses. O grupo apresenta interesse em socializar-se e esse deve ser um exemplo a ser seguido e o primeiro passo para falarmos de comunidades de prática dentro de um programa para formação de professores. Pelo 
desejo e interesse em compartilhar, o grupo tem permitido que outros aprendam e o campo como um todo venha a evoluir. Porém, para um processo de socialização mais efetivo, como o discutido por Schugurenski (2000), o grupo precisa revelar melhor suas reflexões e seus conhecimentos tardios advindos das práticas que postam e que experienciam com os alunos em sala de aula, ainda um pouco mais profundamente do que faziam no início do blog, em 2011, revelando acertos, fracassos, dificuldades e estratégias.

A análise como um todo nos mostra que 9 estados alertam limites que podemos trabalhar, em especial a baixa frequência de comentários ou gestos de interações apresentados por todos os estados e que por isso representam limites do campo tão recente e não do campus exclusivamente. Não há uma exigência ou cultura nos grupos em comentar, ou em responder comentários, apenas há a cultura de postar, nem se trata de objetivo do projeto e entendemos que ele tenha outros objetivos bem importantes. Porém, o que podemos também refletir é que alguns frutos não irão germinar neste ambiente, como aqueles para reflexões em grupo sobre dificuldades cotidianas da prática docente, contribuições externas de ideias inovadoras para a aprendizagem, amadurecimento do próprio grupo com discussões entre eles e amadurecimento do programa e das comunidades PIBID, pela exposição de seus projetos, ações, objetivos e planejamentos, assim como as falhas, acertos e incertezas dos mesmos. Na área da pesquisa também deixamos de germinar dados discursivos para as investigações sobre qualidade da formação docente, aprendizagem docente, desenvolvimento profissional, valorização da docência, tecnologias na educação, e para as análises de comportamento das comunidades de aprendizagem em ambientes informais.

Podemos apontar aqui o modelo de comunidades de prática de Lave e Wenger (1991) e o quão relevante pode ser promovê-lo por intermédio e com auxílio do PIBID/Capes, via esse ambiente e, diríamos, universo, que está se formando para quem quer se tornar professor e aprender coisas sobre ser professor. O PIBID precisa estudá-lo e pensar criativamente a sua integração, tendo entendido que as comunidades de prática se formam por grupos de pessoas que se engajam em processo de aprendizagem coletiva, se interessam por aprender mais e fazer melhor pelo domínio e assim incentivam novas abordagens para os problemas experienciados e fortalecem a área. Trata-se de uma proposta ampla e que se enquadra muito bem frente à riqueza e diversidade de experiências que estão nesses ambientes postas ao silêncio, enquanto um número alto de professores recém-formados ou licenciandos não sabem o que fazer com um rolo de barbante e 30 adolescentes, ou, ainda, não sabem com quem repartir e a partir de onde refletir sua prática.

Devemos considerar que já temos uma grande rede de comunidades docentes, facilmente integradas, com muitos outros estados, e que podem se envolver e evoluir intrínseca e extrinsecamente, ou seja, com a integração dessas comunidades - entre si - os Pibidianos da Biologia, da Física, Química e outras áreas; entre coordenadores gerais, locais, supervisores, 
colaboradores e bolsistas - e com a integração com a comunidade externa - sejam licenciados, professores formados, ex-Pibidianos, pesquisadores, coordenadores e diretores de outros centros e igualmente relevantes para todos nós, aqueles interessados pela transformação da docência e futuros professores.

Entrar nesses ambientes, especialmente no PIBID-C, é destinar-se a um mergulho exploratório da prática docente e da realidade de formação frente a diferentes contextos escolares. Confrontado pelos registros do grupo, mesmo sem intenção e interação, o visitante tem condições de aprender algo sobre a docência, pois se trata de fato de um ambiente informal bem documentado para a aprendizagem docente.

\section{Referências}

ALVES, D. R. S.; PASSOS, M. N.; ARRUDA, S. M. A Educação não formal em periódicos da área de Ensino de Ciências no Brasil (1979-2008). Revista Brasileira de Ensino de Ciência e Tecnologia, v. 3, n.1, jan./abr. p. 16-40, 2010.

ARRUDA, S. M.; PASSOS, M. M.; FREGOLENTE, A. Focos da aprendizagem docente. Alexandria (UFSC), v. 5, p. 25-48, 2012.

ARRUDA, S. M.; PASSOS, M. M.; PIZA, C. M.; FELIX, R. B. O aprendizado científico no cotidiano. Ciência \& Educação, Bauru, v. 19, n. 02, p. 481-498, 2013.

ASTOR-JACK, T.; WHALEY, K. L. K.; DIRKING, L.; PERRY, D. L.; GARIBAY, C. In: Principle-In Practice: Museums as Learning Institutions. Lanham, MD: AltaMira Press, 2007.

BARDIN, L. Análise de conteúdo. Lisboa: Edições 70, 2006.

BRASIL. Ministério da Educação. Seleção pública de propostas de projetos de iniciação à docência voltados ao Programa Institucional de Bolsa de Iniciação à Docência (PIBID). Edital MEC/CAPES/FNDE. 12 dez. 2007.

BOGDAN, R.; BIKLEN, S.K. Qualitative Research for Education. Boston, Allyn and Bacon, Inc., 1982.

CHARLOT, B. Da relação com o saber: elementos para uma teoria. Porto Alegre: Artmed, 2000.

COLLEY, H., HODKINSON, P.; MALCOLM J. Non-formal learning: mapping the conceptual terrain, a consultation report. [Internet]. 2002. Disponível em: <http://www.infed.org/archives/etexts/colley_informal_learning.htm>. Acesso em: 10 fev. 2015.

DEMO, Pedro. Pesquisa participante: saber pensar e intervir juntos. Brasília: Líber Livro, 2008.

LAVE, J.; WENGER, E. Situated Learning: legitimate peripheral participation. Cambridge:

Cambridge University Press, 1991. 
NRC - NATIONAL RESEARCH COUNCIL. Learning science in informal environments: people, places, and pursuits. National research council. Washington, DC: The National Academies Press, 2009.

PEDRO, C. L. Sites de Redes Sociais como Ambiente Informal de Aprendizagem Científica. 2013.

Dissertação (Mestrado em Ensino de Ciências e Educação Matemática) - Universidade Estadual de Londrina, Londrina, 2013.

PIBID/[...] - CIÊNCIAS 2011. PIBID Ciências. [Blog]. Disponível em:

<http://pibidciencias[...].blogspot.com.br/>. Acesso em: 10 fev. 2015.

SCHUGURENSKY, D. the forms of informal learning: towards a conceptualization of the field.

Canada: Centre for the Study of Education and Work. WALL Working Paper, n.19, 2000.

WENGER, E. Uma teoria social da aprendizagem. In: ILLERIS, K. (Org.). Teorias contemporâneas da aprendizagem. Porto Alegre: Penso, 2013.

Elaine da Silva Machado. Especialista em Docência na Educação Superior e Mestranda em Ensino de Ciências e Educação Matemática. Universidade Estadual de Londrina - UEL. Com apoio da Capes. elainemachado.bio@gmail.com

Sergio de Mello Arruda. Doutor em Educação pela Universidade de São Paulo - USP - SP. Professor do Departamento de Física da Universidade Estadual de Londrina - UEL. Com apoio do CNPq. sergioarruda@sercomtel.com.br

Marinez Meneghello Passos. Doutora em Educação para a Ciência pela Universidade Estadual Paulista "Júlio de Mesquita Filho" - Unesp - Bauru. Professora do Departamento de Matemática da Universidade Estadual de Londrina - UEL. Com apoio da Fundação Araucária. marinezmp@sercomtel.com.br

Virginia lara de Andrade Maistro. Doutora em Ensino de Ciências e Educação Matemática pela Universidade Estadual de Londrina - UEL. Professora do Departamento de Biologia Geral da Universidade Estadual de Londrina - UEL. virginiamaistro@yahoo.com.br 